\title{
Determinants of alternate-level-of-care delayed discharge among acute care survivors of hypoxic-ischemic brain injury: a population-based cohort study
}

\author{
David Stock PhD, Cassandra Cowie BA, Vincy Chan MPH, Angela Colantonio PhD OT, \\ Walter P. Wodchis PhD, David Alter PhD, Nora Cullen MD
}

Abstract

Background: Delayed discharge, captured as alternate-level-of-care days, represents inefficient use of high-demand acute care resources and results in potentially poorer patient outcomes. We performed a study to determine the extent of alternate-level-of-care days among patients who survived hypoxic-ischemic brain injury in inpatient hospital care in Ontario and to identify predictors of alternate-level-of-care use in this population.

Methods: A population-based cohort of acute care survivors of hypoxic-ischemic brain injury aged 20 years or more from $2002 / 03$ through 2011/12 was identified. We used 2 case definitions, the more specific identifying patients with a most responsible diagnosis of "anoxic brain damage," and the more sensitive capturing additional likely causative conditions as the most responsible diagnosis. Multivariable zero-inflated negative binomial regression was used to estimate independent effects on the relative incidence of alternatelevel-of-care days.

Results: We identified 491 patients using the specific case definition and 669 patients using the extended case definition. After deaths were excluded, 232 patients $(47.2 \%)$ and 278 patients $(41.6 \%)$, respectively, had at least 1 alternate-level-of-care day (median 20 and $19 \mathrm{~d}$, respectively). In both cohorts, decreasing age, no special care unit hours and acute care episode earlier in the study period were predictive of increased alternate-level-of-care days relative to length of stay. Discharge disposition and psychiatric/ behavioural comorbidity were most predictive of having any alternate-level-of-care days.

Interpretation: Patients with hypoxic-ischemic brain injury had a greater proportion of alternate-level-of-care days than has been reported for patients with other types of acquired brain injury. This finding suggests that substantial barriers to appropriate discharge exist for this population. Predictors of increased alternate-level-of-care days were also shown to be unique. Further study of care deficits among patients with hypoxic-ischemic brain injury is warranted.

lternate-level-of-care acute care beds are those occupied by patients who no longer require acute care services, as designated by the attending physician. ${ }^{1}$ Delayed discharge is costly not only for the health care system but also for patients awaiting more appropriate treatment. ${ }^{2,3}$ Alternate-level-of-care use has become an important policy issue in Canada. A recent report by the Canadian Institute for Health Information showed that there were more than 1.7 million alternate-level-of-care days (involving 74000 patients) in 2007-2008 alone in Canada (excluding Quebec and Manitoba), accounting for $14 \%$ of hospital days in acute care facilities. ${ }^{1}$ Previous research has identified that increasing age, comorbidity burden, and cognitive/behavioural and neurologic diagnoses are associated with alternatelevel-of-care days. ${ }^{1,4,5}$ Within the acquired brain injury population, having a nontraumatic brain injury (e.g., resulting from hypoxia-anoxia, ischemia or tumours) is more strongly associated with alternate-level-of-care days than traumatic brain injury (e.g., resulting from physical trauma or head injury). ${ }^{4}$ Furthermore, among patients with nontraumatic brain injury in Ontario, the odds of having an alternate-levelof-care day increased by $19 \%$ from 2007 to $2009 .{ }^{4}$ As nontraumatic brain injury constitutes a heterogeneous patient group with varied acute care requirements, a more thorough

Competing interests: None declared.

This article has been peer reviewed.

Correspondence to: Nora Cullen, nora.cullen@uhn.ca

CMAJ Open 2016. DOI:10.9778/cmajo.20150123 
understanding of alternate-level-of-care use across subtypes of nontraumatic brain injury is needed. ${ }^{6}$

Hypoxic-ischemic brain injury is a nontraumatic brain injury that results from sustained oxygen deprivation arising from ischemic (i.e., restricted blood flow) or anoxic/hypoxic (i.e., no/low oxygen irrespective of ischemia) origins. The most common cause is cardiac arrest, although other injuries substantially impeding blood oxygenation or circulation to neural tissue (e.g., respiratory arrest, carbon monoxide poisoning) and asphyxia can also result in hypoxic-ischemic brain injury. ${ }^{7,8}$ Outcomes among survivors of hypoxic-ischemic brain injury are often poor and include long-term motor, cognitive and psychosocial impairments. ${ }^{9}$

The prevalence of hypoxic-ischemic brain injury within nontraumatic brain injury populations has been estimated at $20 \%$ in older patients. ${ }^{6}$ Furthermore, there is evidence that, owing to advancements in critical care medicine and cardiopulmonary resuscitation, survival rates after anoxic episodes have improved, leading to a growing population of survivors of hypoxic-ischemic brain injury. ${ }^{10-12}$ Nevertheless, there remains a paucity of information on the health care needs and use of health care services of this population, which suggests that clinicians may be ill equipped to assess these patients and provide appropriate and efficient treatment. ${ }^{13}$ This is particularly important for the hypoxic-ischemic brain injury population, as deficits in knowledge and health care resources have been observed to contribute to delayed discharge. ${ }^{14}$ Given that optimal treatment of hypoxic-ischemic brain injury is hindered by knowledge gaps and the overburdened acute care services of Canada's health care system, patients with hypoxicischemic brain injury may represent an understudied group at high risk for alternate-level-of-care use.

The aim of this study was to examine factors associated with acute care alternate-level-of-care days among survivors of hypoxic-ischemic brain injury. Understanding these factors can help identify which patients can benefit most from early discharge planning, enabling more efficient care for these patients and reducing wait times for acute care beds.

\section{Methods}

We conducted a population-based cohort study to investigate alternate-level-of-care use among inpatients with hypoxicischemic brain injury who survived their acute care episode. We evaluated selected demographic and clinical factors of interest as predictors of the likelihood and extent of alternatelevel-of-care days among these patients.

\section{Study design and data sources}

The Ontario Cancer Data Linkage Program ("cd-link") is an initiative of the Ontario Institute for Cancer Research/Cancer Care Ontario Health Services Research Program. Under this program, risk-reduced coded data from the Institute for Clinical Evaluative Sciences Data Repository are provided directly to researchers with the protections of a comprehensive data use agreement. We used the Canadian Institute for Health Information Discharge Abstract Database to identify acute care episodes of hypoxic-ischemic brain injury from Ontario from 2002/03 through 2011/12 inclusive. This populationbased health care administrative database captures demographic and clinical information on all hospital admissions and discharges, including deaths and transfers, using standard diagnosis, procedure and intervention codes. Given the low frequency of alternate level of care in the pediatric population, we limited our cohort to adults aged 20 or older.

\section{Case definition}

We used International Classification of Diseases, 10th Revision, Canada (ICD-10-CA) coding to identify patients with hypoxic-ischemic brain injury. The specific case definition corresponded to the presence of an "anoxic brain damage" code (G93.1) in the most responsible diagnosis field. We also used a second, more sensitive, case definition (extended), which included plausibly causal hypoxic-ischemic brain injury conditions in the most responsible diagnosis field coincident with G93.1 in up to 24 secondary diagnosis fields. These conditions included cardiac (I46.0) and respiratory (R09.0 and R09.2) arrest, asphyxia (T71, T17 and T75.1) and conditions likely to involve anoxia (G92, T58 and T70.2).

\section{Predictor variables of interest}

Demographic variables included age, sex, income quintile by census region and rurality. Clinical characteristics included comorbidity burden and time spent in special care units as an indicator of injury severity, as previous research has found these to be associated with alternate-level-of-care use. ${ }^{1,4} \mathrm{We}$ captured comorbidity burden and prior use of health care services using the Johns Hopkins Aggregated Diagnosis Groups. We measured extent of use of health care services using the Johns Hopkins Adjusted Clinical Groups Resource Utilization Bands, ${ }^{15,16}$ and we derived a comorbidity index from a weighted sum of Aggregated Diagnosis Groups accumulated over the 2 years before the admission for the acute care episode related to the hypoxic-ischemic brain injury. ${ }^{17}$ We measured psychiatric/ behavioural comorbidity as the presence of any ICD-10-CA F chapter heading code in any Discharge Abstract Database diagnostic field. ${ }^{4}$ We considered discharge disposition from acute care, as it has been shown to affect propensity toward alternate-level-of-care days. ${ }^{4}$ In addition, we assessed fiscal year of discharge to capture trends in alternate-level-of-care use with calendar time and to adjust for associated residual confounding. We chose these variables based on previous research in the acquired brain injury population and data availability of the Discharge Abstract Database. ${ }^{1,4,5}$

\section{Main outcome}

The outcome of interest was number of alternate-level-of-care days during the acute care episode captured in the Discharge Abstract Database.

\section{Statistical analysis}

We used multivariable zero-inflated negative binomial regression to estimate independent effects of predictors on relative incidence of alternate-level-of-care days, to account for a 
large proportion of zeros (i.e., no alternate-level-of-care days) in the dependent variable. ${ }^{18,19}$ Zero-inflated models allow separate parameterization of count (i.e., number of alternatelevel-of-care days) and binary (i.e., zero v. nonzero alternatelevel-of-care days) processes. A portion of zero outcomes are modelled as part of the count process, which distinguishes this model from other zero-inflated count outcome models (e.g., hurdle models). We selected the negative binomial distribution over the Poisson distribution because of remaining overdispersion, verified by the Pearson $\chi^{2}$ test, a highly statistically significant measure of dispersion in the zero-inflated negative binomial model and suspiciously small standard errors from the zero-inflated Poisson model. We used visual inspection (e.g., plotting observed v. model-predicted alternate-level-ofcare days) and log-likelihood-based indicators of goodness of fit to guide selection of zero-inflated over standard negative binomial models. We included the natural logarithm of the length of stay, in days, of the acute care episode as an offset variable. We used SAS version 9.3 for all analyses.

\section{Ethics approval}

Ethics approval was obtained from the University Health Network Research Ethics Board.

\section{Results}

We identified 2343 patients using the specific case definition and 3228 patients using the extended case definition in Ontario's acute care settings between 2002/03 and 2011/12. Almost $80 \%$ of patients (1850 and 2533 , respectively) died during the acute care episode; 76/2343 (3.2\%) had at least 1 alternatelevel-of-care day. We did not observe an increase in the proportion of patients with hypoxic-ischemic brain injury who survived their acute care episode over the study period (linear trend across fiscal year categories for the extended cohort: $p=$ 0.36 ); however, there was a strong trend toward increasing proportion of patients with hypoxic-ischemic brain injury who died with increasing age $(p<0.001)$. After we excluded deaths, there were 493 and 675 patients in the specific and extended case definition cohorts, respectively (Figure 1). Two patients from the former cohort and 6 patients from the latter cohort were excluded because of missing data, leaving 491 and 669 patients, respectively.

Most patients were aged 50-79 years, with the largest category being $50-64$ years.

Table 1 shows the acute care days for the 2 cohorts across potential predictors of alternate-level-of-care days. A total of 232 patients $(47.2 \%)$ in the specific case definition cohort and 278 patients $(41.6 \%)$ in the extended case definition cohort had at least 1 alternate-level-of-care day (median 20 [interquartile range 2-41.5] days and 19 [interquartile range 8-40] days, respectively). Distributions of length of stay were also positively skewed: the median length of stay was 30 (interquartile range 13-61) days for the specific case definition cohort and 27 (interquartile range 27-55) days for the extended case definition cohort. Figure 2 shows the number of alternate-level-of-care days to overall length of stay over the study period.

Multivariable adjusted incidence rate ratios of alternatelevel-of-care days per length of stay are presented in Table 2.

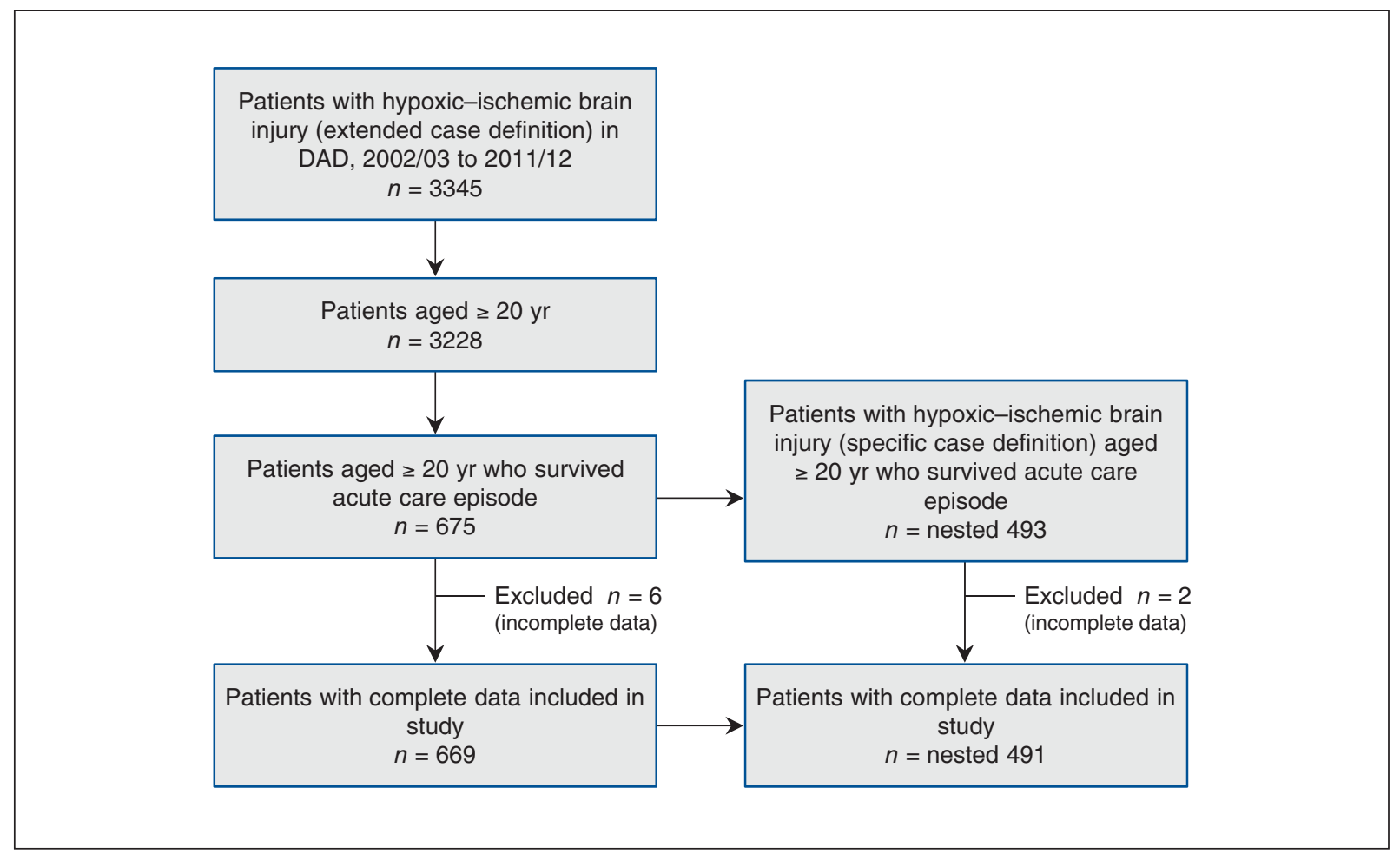

Figure 1: Flow chart showing derivation of study cohorts. DAD = Discharge Abstract Database. 


\section{OPEN}

\begin{tabular}{|c|c|c|c|c|}
\hline \multirow[b]{2}{*}{ Characteristic } & \multicolumn{2}{|c|}{$\begin{array}{l}\text { Specific case definition } \\
\qquad(n=491)\end{array}$} & \multicolumn{2}{|c|}{$\begin{array}{l}\text { Extended case definition } \\
\qquad(n=669)\end{array}$} \\
\hline & $\begin{array}{c}\text { Acute care days } \\
(\%) \\
(n=23576)\end{array}$ & $\begin{array}{l}\text { No. }(\%) \text { of } \\
\text { patients }\end{array}$ & $\begin{array}{c}\text { Acute care days } \\
\qquad \begin{array}{c}(\%) \\
(n=29251)\end{array}\end{array}$ & $\begin{array}{c}\text { No. }(\%) \text { of } \\
\text { patients }\end{array}$ \\
\hline \multicolumn{5}{|l|}{ Age at admission, yr } \\
\hline 20-34 & $2535(10.8)$ & $48(9.8)$ & $2719(9.3)$ & $61(9.1)$ \\
\hline $35-49$ & $4969(21.1)$ & $98(20.0)$ & $5930(20.3)$ & $124(18.5)$ \\
\hline $50-64$ & $8046(34.1)$ & $154(31.4)$ & 9407 (32.2) & 207 (30.9) \\
\hline $65-79$ & $6432(27.3)$ & $146(29.7)$ & $8642(29.5)$ & 212 (31.2) \\
\hline$\geq 80$ & $1594(6.8)$ & $45(9.2)$ & $2553(8.7)$ & $65(9.7)$ \\
\hline \multicolumn{5}{|l|}{ Sex } \\
\hline Female & $8500(36.0)$ & $175(35.6)$ & $10190(34.8)$ & $228(34.1)$ \\
\hline Male & $15076(63.9)$ & $316(64.4)$ & $19061(65.2)$ & $441(65.9)$ \\
\hline \multicolumn{5}{|l|}{ Income quintile } \\
\hline Urban quintile 1 (lowest) & $6560(27.8)$ & $142(28.9)$ & 7650 (26.2) & $181(27.0)$ \\
\hline Urban quintile 2 & $5584(23.7)$ & $107(21.8)$ & $6970(23.8)$ & $144(21.5)$ \\
\hline Urban quintile 3 & $3895(16.5)$ & $88(17.9)$ & 4954 (16.9) & $123(18.4)$ \\
\hline Urban quintile 4 & $4618(19.6)$ & $90(18.3)$ & 6104 (20.9) & $134(20.0)$ \\
\hline Urban quintile 5 (highest) & 2919 (12.4) & $64(13.0)$ & 3573 (12.2) & $87(13.0)$ \\
\hline \multicolumn{5}{|l|}{ Rurality } \\
\hline Yes & $1322(5.6)$ & $53(10.8)$ & $1547(5.3)$ & $64(9.6)$ \\
\hline No & $22254(94.4)$ & $438(89.2)$ & $27704(94.7)$ & $605(90.4)$ \\
\hline \multicolumn{5}{|l|}{$\begin{array}{l}\text { Adjusted Clinical Groups } \\
\text { Resource Utilization Bands }\end{array}$} \\
\hline None or healthy & $1772(7.5)$ & $26(5.3)$ & $1990(6.8)$ & $38(5.7)$ \\
\hline Low & $1118(4.7)$ & $28(5.7)$ & $1559(5.3)$ & $41(6.1)$ \\
\hline Moderate & $7301(31.0)$ & $158(32.2)$ & 9407 (32.2) & $225(33.6)$ \\
\hline High & $6282(26.6)$ & $120(24.4)$ & 7717 (26.4) & $164(24.5)$ \\
\hline Very high & $7103(30.1)$ & 159 (32.4) & 8578 (29.3) & $201(30.0)$ \\
\hline \multicolumn{5}{|l|}{$\begin{array}{l}\text { Aggregated Diagnosis Groups } \\
\text { comorbidity index }\end{array}$} \\
\hline$\leq 0$ & $3428(14.5)$ & $66(13.4)$ & $4094(14.0)$ & 89 (13.3) \\
\hline $1-10$ & $4469(19.0)$ & $84(17.1)$ & $5703(19.5)$ & $124(18.5)$ \\
\hline $11-20$ & $4634(19.7)$ & $97(19.8)$ & 6095 (20.8) & 149 (22.3) \\
\hline $21-30$ & $5172(21.9)$ & $116(23.6)$ & $6370(21.8)$ & $150(22.4)$ \\
\hline$>30$ & $5873(24.9)$ & $128(26.1)$ & 6989 (23.9) & $157(23.5)$ \\
\hline \multicolumn{5}{|l|}{ Special care hours } \\
\hline 0 & 2801 (11.9) & $82(16.7)$ & $3165(10.8)$ & $92(13.8)$ \\
\hline $1-99$ & $1063(4.5)$ & $57(11.6)$ & $1634(5.6)$ & $83(12.4)$ \\
\hline 100-399 & $5783(24.5)$ & $160(32.6)$ & 7245 (24.8) & 227 (33.9) \\
\hline$\geq 400$ & $13929(59.1)$ & $192(39.1)$ & 17207 (58.8) & 267 (39.9) \\
\hline
\end{tabular}

After we accounted for excess zero outcomes, patients aged 20-34 years had higher rates of alternate-level-of-care days per length of stay than did those aged 65-79; the linear trend was statistically significant for both cohorts. Patients with no special care unit hours had significantly more alternate-levelof-care days per length of stay than did patients with 400 or more special care unit hours. There was suggestion of an increasingly inverse association between fiscal year and 


\begin{tabular}{|c|c|c|c|c|}
\hline \multirow[b]{2}{*}{ Characteristic } & \multicolumn{2}{|c|}{$\begin{array}{l}\text { Specific case definition } \\
\qquad(n=491)\end{array}$} & \multicolumn{2}{|c|}{$\begin{array}{l}\text { Extended case definition } \\
\qquad(n=669)\end{array}$} \\
\hline & $\begin{array}{c}\text { Acute care days } \\
(\%) \\
(n=23576)\end{array}$ & $\begin{array}{l}\text { No. }(\%) \text { of } \\
\text { patients }\end{array}$ & $\begin{array}{c}\text { Acute care days } \\
\qquad \begin{array}{c}(\%) \\
(n=29251)\end{array}\end{array}$ & $\begin{array}{l}\text { No. }(\%) \text { of } \\
\text { patients }\end{array}$ \\
\hline \multicolumn{5}{|l|}{ Discharge disposition } \\
\hline Home & $3472(14.7)$ & $86(17.5)$ & $5173(17.7)$ & $153(22.9)$ \\
\hline Rehabilitation & $6247(26.5)$ & $119(24.2)$ & $7464(25.5)$ & $140(20.9)$ \\
\hline Long-term care & $11661(49.5)$ & $173(35.2)$ & $13446(46.0)$ & $199(29.7)$ \\
\hline Other & 2196 (9.3) & $113(23.0)$ & $3168(10.8)$ & $177(26.4)$ \\
\hline \multicolumn{5}{|c|}{$\begin{array}{l}\text { Psychiatric/behavioural } \\
\text { comorbidity }\end{array}$} \\
\hline Absent & $16135(68.4)$ & $353(71.9)$ & 20691 (70.7) & $500(74.7)$ \\
\hline Present & $7441(31.6)$ & $138(28.1)$ & $8560(29.3)$ & 169 (25.3) \\
\hline \multicolumn{5}{|l|}{ Fiscal year(s) } \\
\hline $2002 / 03$ & 4109 (17.4) & $108(22.0)$ & $4847(16.6)$ & $137(20.5)$ \\
\hline $2004 / 05$ & $4384(18.6)$ & $97(19.8)$ & $5180(17.7)$ & $123(18.4)$ \\
\hline $2006 / 07$ & $3762(16.0)$ & $95(19.4)$ & $4827(16.5)$ & $131(19.6)$ \\
\hline $2008 / 09$ & $6642(28.2)$ & $104(21.2)$ & 7678 (26.2) & $138(20.6)$ \\
\hline 2010/11-2011/12 & 4679 (19.8) & $87(17.7)$ & $6719(23.0)$ & 140 (20.9) \\
\hline
\end{tabular}

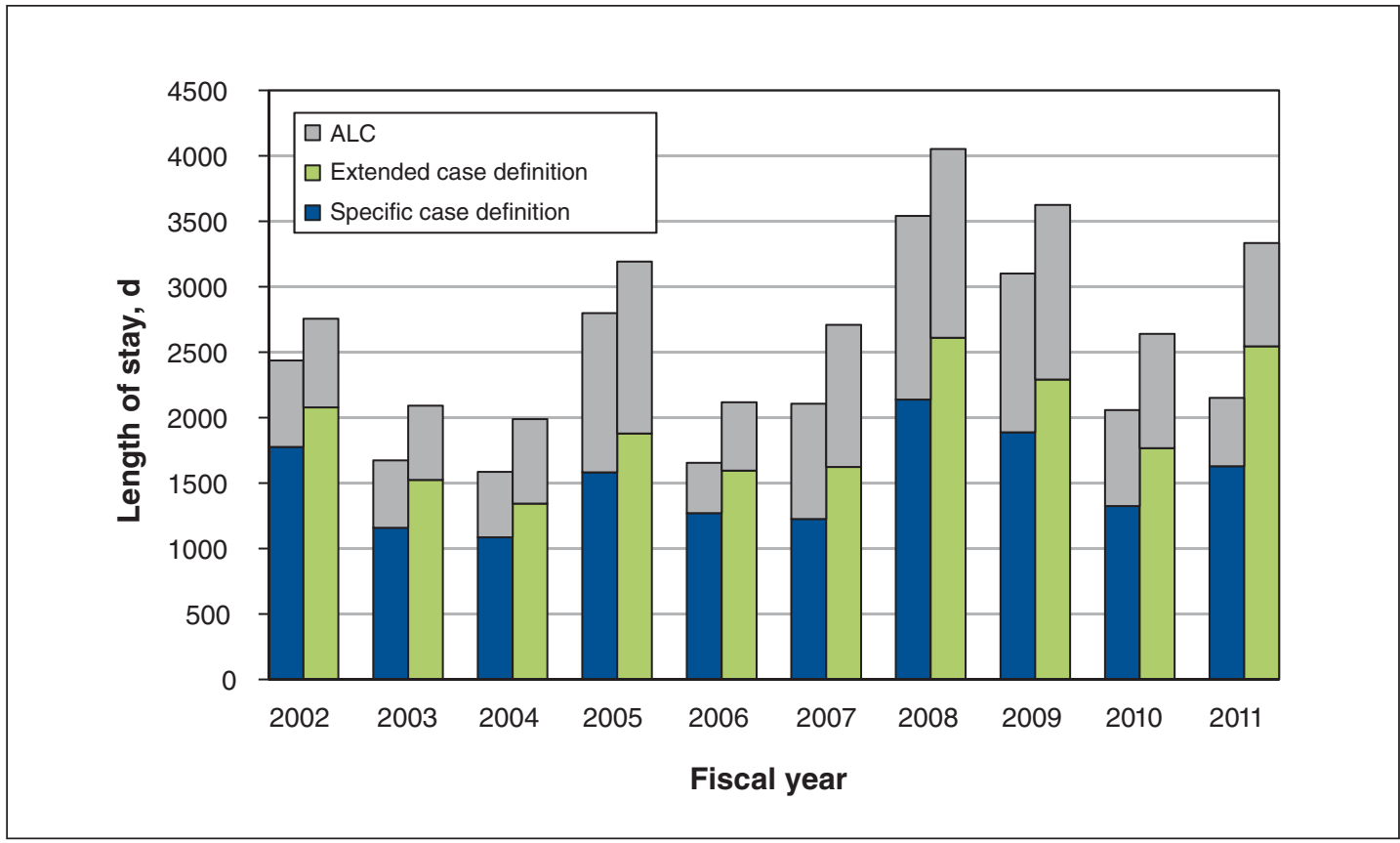

Figure 2: Cumulative length of acute care episode for the specific and extended case definition cohorts, by fiscal year. Proportion of length of stay spent in an alternate-level-of-care (ALC) bed is shown. Data for 2012 were excluded because of truncation of the study period, which resulted in incomplete data for that fiscal year.

number of alternate-level-of-care days per length of stay, corroborated by indication of a decreasing linear trend over time $(p=0.06)$. Low prior use of health care resources was associated with fewer alternate-level-of-care days per length of stay, although only for the specific case definition cohort. Rates of alternate-level-of-care days per length of stay were statistically significantly lower for patients in the low Adjusted Clinical Groups Resource Utilization Bands category. 


\begin{tabular}{|c|c|c|c|c|}
\hline \multirow[b]{2}{*}{ Variable } & \multicolumn{2}{|c|}{ Specific case definition } & \multicolumn{2}{|c|}{ Extended case definition } \\
\hline & Rate ratio $(95 \% \mathrm{Cl})$ & $p$ trend & Rate ratio $(95 \% \mathrm{Cl})$ & $p$ trend \\
\hline Age, yr & & 0.02 & & 0.01 \\
\hline $20-34$ & $1.38(1.02-1.88)$ & & $1.44(1.05-1.97)$ & \\
\hline $35-49$ & $1.20(0.94-1.52)$ & & $1.30(1.02-1.64)$ & \\
\hline $50-64$ & $1.12(0.90-1.38)$ & & $1.14(0.93-1.40)$ & \\
\hline 65-79 (reference) & 1.00 & & 1.00 & \\
\hline$\geq 80$ & $0.99(0.73-1.35)$ & & $1.09(0.82-1.43)$ & \\
\hline \multicolumn{5}{|l|}{ Sex } \\
\hline Male (reference) & 1.00 & & 1.00 & \\
\hline Female & $1.00(0.84-1.19)$ & & $0.99(0.83-1.17)$ & \\
\hline $\begin{array}{l}\text { Adjusted Clinical Groups } \\
\text { Resource Utilization Bands }\end{array}$ & & 0.15 & & 0.22 \\
\hline None & $0.94(0.66-1.35)$ & & $0.92(0.64-1.32)$ & \\
\hline Low & $0.56(0.37-0.84)$ & & $0.78(0.53-1.15)$ & \\
\hline Moderate & $0.95(0.77-1.18)$ & & $0.93(0.76-1.14)$ & \\
\hline High & $1.08(0.86-1.36)$ & & $1.07(0.86-1.33)$ & \\
\hline Very high (reference) & 1.00 & & 1.00 & \\
\hline Special care hours & & 0.001 & & 0.002 \\
\hline 0 & $1.57(1.21-2.03)$ & & $1.49(1.15-1.92)$ & \\
\hline $1-99$ & $1.10(0.78-1.56)$ & & $1.15(0.83-1.57)$ & \\
\hline 100-399 & $1.13(0.91-1.40)$ & & $1.11(0.89-1.37)$ & \\
\hline$\geq 400$ (reference) & 1.00 & & 1.00 & \\
\hline \multicolumn{5}{|l|}{$\begin{array}{l}\text { Psychiatric/behavioural } \\
\text { comorbidity }\end{array}$} \\
\hline Absent (reference) & 1.00 & & 1.00 & \\
\hline Present & $1.12(0.93-1.34)$ & & $1.10(0.92-1.32)$ & \\
\hline Fiscal year & & 0.06 & & 0.06 \\
\hline $2002 / 03$ & $1.29(0.97-1.72)$ & & $1.23(0.93-1.62)$ & \\
\hline $2004 / 05$ & $1.34(1.01-1.78)$ & & $1.31(1.00-1.71)$ & \\
\hline $2006 / 07$ & $1.07(0.82-1.40)$ & & $1.13(0.87-1.46)$ & \\
\hline $2008 / 09$ & $1.18(0.92-1.52)$ & & $1.06(0.84-1.34)$ & \\
\hline 2010/11-2011/12 (reference) & 1.00 & & 1.00 & \\
\hline
\end{tabular}

Predictors of no alternate-level-of-care days (i.e., binary process of zero-inflated multivariable models) for the specific case definition cohort were rurality, special care unit hours, discharge disposition and psychiatric/behavioural comorbidity; predictors for the extended case definition cohort were discharge disposition and psychiatric/behavioural comorbidity (Table 3). The strongest predictor of having no alternate-level-of-care days was discharge disposition. Patients expected to be released home or transferred to other acute care had substantially lower likelihoods of spending time in an alternate-level-of-care bed than did those destined for palliative, continuing or long-term care. Last, having psychiatric/behavioural comorbidity was signif- icantly associated with any alternate-level-of-care days for both cohorts.

\section{Interpretation}

We found that nearly 1 in 2 patients with hypoxic-ischemic brain injury who survived the acute care episode had at least 1 alternate-level-of-care day, with a median of 20 days. Significant predictors of having more alternate-level-of-care days relative to length of stay included being younger, spending no time in a special care unit and having an acute care episode earlier in the study period. This last predictor suggests that care for this population has become more efficient in recent 


\begin{tabular}{|c|c|c|}
\hline \multirow[b]{2}{*}{ Predictor } & \multicolumn{2}{|c|}{ Adjusted odds ratio $(95 \% \mathrm{Cl})$} \\
\hline & $\begin{array}{l}\text { Specific case } \\
\text { definition }\end{array}$ & $\begin{array}{l}\text { Extended } \\
\text { case } \\
\text { definition }\end{array}$ \\
\hline \multicolumn{3}{|l|}{ Rurality } \\
\hline Urban (reference) & 1.00 & NR \\
\hline Rural & $\begin{array}{c}2.11 \\
(0.96-4.63)\end{array}$ & \\
\hline \multicolumn{3}{|l|}{ Special care hours } \\
\hline None & $\begin{array}{c}2.14 \\
(1.15-3.99)\end{array}$ & NR \\
\hline $1-99$ & $\begin{array}{c}1.74 \\
(0.73-4.15)\end{array}$ & \\
\hline 100-399 & $\begin{array}{c}1.44 \\
(0.85-2.42)\end{array}$ & \\
\hline$\geq 400$ (reference) & 1.00 & \\
\hline \multicolumn{3}{|l|}{ Discharge disposition } \\
\hline Home & $\begin{array}{c}6.11 \\
(3.25-11.5)\end{array}$ & $\begin{array}{c}7.21 \\
(4.32-12.0)\end{array}$ \\
\hline Rehabilitation & $\begin{array}{c}1.51 \\
(0.87-2.63)\end{array}$ & $\begin{array}{c}1.59 \\
(0.97-2.63)\end{array}$ \\
\hline Long-term care (reference) & 1.00 & 1.00 \\
\hline Other & $\begin{array}{c}16.8 \\
(8.17-34.5)\end{array}$ & $\begin{array}{c}24.3 \\
(12.8-46.2)\end{array}$ \\
\hline \multicolumn{3}{|l|}{$\begin{array}{l}\text { Psychiatric/behavioural } \\
\text { comorbidity }\end{array}$} \\
\hline Absent (reference) & 1.00 & 1.00 \\
\hline Present & $\begin{array}{c}0.56 \\
(0.34-0.93)\end{array}$ & $\begin{array}{c}0.59 \\
(0.38-0.92)\end{array}$ \\
\hline
\end{tabular}

years. Spending any time in an alternate-level-of-care bed was most strongly associated with waiting for subsequent care and having a psychiatric/behavioural comorbid condition.

Our rate of nearly $50 \%$ of survivors of hypoxic-ischemic brain injury with an alternate-level-of-care day is a disproportionately higher rate than reported in previous research. The Canadian Institute for Health Information found that 2\% (in Prince Edward Island) to 7\% (in Ontario) of hospital stays in 2007-2008 involved alternate-level-of-care use. ${ }^{1}$ Chen and colleagues ${ }^{4}$ found that, from 2007 to $2009,14 \%$ of patients with nontraumatic brain injury and $17 \%$ of those with traumatic brain injury in Ontario had at least 1 alternate-level-of-care day. In both studies, the median length of stay was 10 days. ${ }^{1,4}$ Higher rates of alternate-level-of-care use among patients with hypoxicischemic brain injury than among patients with traumatic or other acquired brain injuries are concerning, given that care guidelines currently used by clinicians to manage these injuries are based on best practices for traumatic brain injury. ${ }^{10}$
Even compared to other subpopulations of patients with brain injury waiting for discharge to similar post-acute-care settings, patients with hypoxic-ischemic brain injury show a remarkably higher likelihood of being placed in an alternatelevel-of-care bed and remaining there for a significant period. Although this may be partially due to a lack of appropriate models of care or care resources, these patients may also represent a patient population with severe functional and cognitive impairments that render them resistant to treatment and functional improvement. This is potentially exacerbated by the fact that patients such as these, with a most responsible diagnosis of anoxic brain damage, are suspected to constitute a more severe case mix. Even in the rehabilitation setting, patients with anoxic brain injury have shown slower functional and cognitive recovery than those with traumatic brain injury. ${ }^{9}$ Among acute care patients in alternate-level-of-care beds waiting for discharge to nursing care in a large Ontario health region, most common diagnoses included those associated with reduced capacity in performing activities associated with daily living as well as cognitive impairment, ${ }^{20}$ conditions perhaps highly prevalent among survivors of hypoxic-ischemic brain injury.

The consequences of this finding for resources and patient outcomes are immense. The Ontario Hospital Association estimates a cost of $\$ 450$ per alternate-level-of-care day, which suggests an average per-patient cost of $\$ 9000$ associated with alternate-level-of-care use. ${ }^{21}$ More important, delayed discharge prolongs patient exposure to an environment prone to avoidable adverse events and is associated with poor patient outcomes. ${ }^{2,22}$ The greater likelihood of, and greater time spent in, alternate-level-of-care settings among patients with hypoxic-ischemic brain injury may therefore partly explain why they have a slower rate of recovery and poorer functional outcomes after rehabilitation than do patients with traumatic brain injury. ${ }^{7,923,24}$ As such, policies targeted at accelerating discharge and decreasing alternate-level-of-care use in the hypoxic-ischemic brain injury population are crucial.

Consideration of predictors of alternate-level-of-care days in patients with hypoxic-ischemic brain injury can help address this issue. In line with previous research, ${ }^{1}$ we found that the strongest predictor of any alternate-level-of-care days was discharge disposition. This further supports the need for policies aimed at improving the efficiency of transfer from acute care. Most patients with alternate-level-of-care days in our study were waiting for placement in long-term care. As in other studies, ${ }^{1,4}$ psychiatric/behavioural comorbidity was significantly predictive of having any alternate-level-of-care days, which is particularly important because recent research has shown that patients with nontraumatic brain injury are highly susceptible to mental health diagnoses..$^{24,25}$ Given that mental health diagnoses are predictive of delayed discharge and that both delayed discharge and mental health diagnoses predict poor outcomes after brain injury,,$^{2,26,27}$ attention to this issue in acute care is needed.

Unique predictors of increased alternate-level-of-care days in our study included less severity (as measured by special care unit hours) and younger age. This is in contrast to previous studies, which have consistently shown that increasing age is predictive 


\section{OPEN}

of alternate-level-of-care days or delayed discharge. ${ }^{1,4,5}$ This discrepancy may be largely due to the fact that our patients had more complex care needs, psychiatric/behavioural comorbidity or compromised social support structures, which make the next step in care or discharge more complicated. However, the causes of the observed inverse associations with age and severity are unknown. Although prior work has suggested that younger brain-injured patients are less likely than older patients to be in long-term care, which indicates a preference to retain younger patients in hospital, ${ }^{28}$ patterns of care specific to younger hypoxic-ischemic brain injury populations and their determinants have yet to be identified. Nevertheless, the unique predictors in our study emphasize that policies specific to hypoxicischemic brain injury are needed to address the propensity of this group for alternate-level-of-care use. Effective care strategies for less severe injury and younger patients may be particularly lacking.

\section{Strengths and limitations}

Our findings are representative of the population of Ontario and may or may not be generalizable outside of this province. In addition, a quality assessment of the Discharge Abstract Database indicated perfect or near-perfect agreement for nonclinical variables and moderate to substantial agreement for the most responsible diagnosis. ${ }^{29}$ Furthermore, use of multivariable zero-inflated count outcome regression permitted a more informative assessment of predictors explaining alternate-level-of-care rates among patients with hypoxic-ischemic brain injury likely to have any alternate-level-of-care days. In particular, without the use of zero-inflated regression, we would not have been able to detect increased rates of alternatelevel-of-care days among younger patients.

Limitations included that fact that our study relied on administrative health data. Although reporting of alternate-level-ofcare days was recently found to be $100 \%$ reliable, ${ }^{30}$ there is concern that alternate-level-of-care use may be underreported, which may result in misclassification of the outcome; this may potentially attenuate effect sizes for some of the predictors. Also, some variables of interest (e.g., ethnicity) were not available in the Discharge Abstract Database. Although there is no widely accepted validated measure of severity of hypoxic-ischemic brain injury, measures that may more directly capture variation in this construct, such as duration and intensity of acute cerebral hypoxia, may have resulted in more accurate independent effect estimates from multivariable models. Furthermore, there may be other important patient-level factors associated with increased alternate-level-of-care use, such as availability of social support and caregiver distress, ${ }^{20}$ that may be prevalent among survivors of hypoxic-ischemic brain injury. Moreover, there is no empirically validated clinical case definition or formal diagnostic criterion for hypoxic-ischemic brain injury. The ICD-10-CA code for anoxic brain damage (G93.1) connotes too strongly its severity, which may exclude less severe injuries that do not involve anoxia but, rather, hypoxia or hypoxia-ischemia. ${ }^{8}$ We attempted to increase the sensitivity of our outcome by including the broader extended case definition. However, a substantial proportion of milder, clinically relevant cases of hypoxic-ischemic brain injury may have been missed. This limitation could explain why our data did not corroborate the previously reported increase in survival over the study period. ${ }^{10-12}$

\section{Conclusion}

Our study provides important information regarding the likelihood of alternate-level-of-care use within the subgroup of patients with hypoxic-ischemic brain injury and the unique predictors of this outcome. The finding that these patients tend to wait in alternate-level-of-care beds, primarily for long-term care placement, shows that resource allocation and appropriate discharge options for this group are limited. The identified potential predictors of alternate-level-of-care use suggest that extrapolating data from other acquired brain injury populations has not and will not satisfactorily address delayed discharge, and acute care deficits in general, in patients with hypoxic-ischemic brain injury.

\section{References}

1. Alternate level of care in Canada: analysis in brief. Ottawa: Canadian Institute for Health Information; 2009. Available: https://secure.cihi.ca/free products/ALC_AIB_FINAL.pdf (accessed 2015 May 30).

2. Worthington $\overline{A D}$, Oldham JB. Delayed discharge from rehabilitation after brain injury. Clin Rebabil 2006;20:79-82.

3. Kunik CL, Flowers L, Kazanjian T. Time to rehabilitation admission and associated outcomes for patients with traumatic brain injury. Arch Phys Med Rehabil 2006;87:1590-6.

4. Chen A, Zagorski B, Chan V, et al. Acute care alternate-level-of-care days due to delayed discharge for traumatic and non-traumatic brain injuries. Healthc Policy 2012;7:41-55.

5. DeCoster C, Roos NP, Carrière $\mathrm{KC}$, et al. Inappropriate hospital use by patients receiving care for medical conditions: targeting utilization review. CMA7 1997; 157:889-96.

6. Chan V, Zagorski B, Parsons D, et al. Older adults with acquired brain injury: a population based study. BMC Geriatr 2013;13:97.

7. Howard RS, Holmes PA, Koutroumanidis MA. Hypoxic-ischaemic brain injury. Pract Neurol 2011;11:4-18.

8. Fitzgerald A, Aditya H, Prior A, et al. Anoxic brain injury: clinical patterns and functional outcomes. A study of 93 cases. Brain Inj 2010;24:1311-23.

9. Cullen NK, Crescini C, Bayley MT. Rehabilitation outcomes after anoxic brain injury: a case-controlled comparison with traumatic brain injury. $P M R$ 2009;1:1069-76

10. Chan PS, McNally B, Tang F, et al.; CARES Surveillance Group. Recent trends in survival from out-of-hospital cardiac arrest in the United States. Circulation 2014;130:1876-82.

11. Daya MR, Schmicker RH, Zive DM, et al. Out-of-hospital cardiac arrest survival improving over time: results from the Resuscitation Outcomes Consortium (ROC). Resuscitation 2015;91:108-15.

12. Wong MK, Morrison LJ, Qiu F, et al. Trends in short- and long-term survival among out-of-hospital cardiac arrest patients alive at hospital arrival. Circulation 2014;130:1883-90.

13. Arciniegas DB. Hypoxic-ischemic brain injury: addressing the disconnect between pathophysiology and public policy. NeuroRebabilitation 2010;26:1-4.

14. Hammond CL, Pinnington LL, Phillips MF. A qualitative examination of inappropriate hospital admissions and lengths of stay. BMC Health Serv Res 2009;9:44.

15. Zielinski A, Kronogård M, Lenhoff H, et al. Validation of ACG case-mix for equitable resource allocation in Swedish primary health care. BMC Public Health 2009;9:347.

16. Brilleman SL, Salisbury C. Comparing measures of multimorbidity to predict outcomes in primary care: a cross sectional study. Fam Pract 2013;30:172-8.

17. Austin PC, van Walraven C, Wodchis WP, et al. Using the Johns Hopkins Aggregated Diagnosis Groups (ADGs) to predict mortality in a general adult population cohort in Ontario, Canada. Med Care 2011;49:932-9.

18. Rose CE, Martin SW, Wannemuehler KA, et al. On the use of zero-inflated and hurdle models for modeling vaccine adverse event count data. 7 Biopharm Stat 2006; 16:463-81.

19. Hu MC, Pavlicova M, Nunes EV. Zero-inflated and hurdle models of count data with extra zeros: examples from an HIV-risk reduction intervention trial. Am 7 Drug Alcohol Abuse 2011;37:367-75.

20. Costa AP, Poss JW, Peirce T, et al. Acute care inpatients with long-term delayed-discharge: evidence from a Canadian health region. BMC Health Serv Res 2012;12:172. 
21. Discharge of hospital patients. In: 2010 annual report of the Office of the Auditor General of Ontario. Toronto: Queen's Printer for Ontario; 2010:64-93. Available: www.auditor.on.ca/en/content/annualreports/arreports/en10/302en10.pdf (accessed 2016 Nov. 14).

22. Baker GR, Norton PG, Flintoft V, et al. The Canadian Adverse Events Study: the incidence of adverse events among hospital patients in Canada. CMA7 2004;170:1678-86.

23. Cullen NK, Weisz K. Cognitive correlates with functional outcomes after anoxic brain injury: a case-controlled comparison with traumatic brain injury. Brain Inj 2011;25:35-43.

24. Colantonio A, Gerber G, Bayley M, et al. Differential profiles for patients with traumatic and non-traumatic brain injury. 7 Rehabil Med 2011;43:311-5.

25. Wilson M, Staniforth A, Till R, et al. The psychosocial outcomes of anoxic brain injury following cardiac arrest. Resuscitation 2014;85:795-800.

26. Rapoport MJ, Kiss A, Feinstein A. The impact of major depression on outcome following mild-to-moderate traumatic brain injury in older adults. 7 Affect Disord 2006;92:273-6.

27. Rogers JM, Read CA. Psychiatric comorbidity following traumatic brain injury. Brain Inj 2007;21:1321-33.

28. Colantonio A, Hsueh J, Petgrave J, et al. A profile of patients with traumatic brain injury within home care, long-term care, complex continuing care, and institutional mental health settings in a publicly insured population. 7 Head Trauma Rehabil 2015;30:E18-29.

29. Juurlink D, Preyra C, Croxford R, et al. Canadian Institute for Health Information Discharge Abstract Database: a validation study. Toronto: Institute for Clinical Evaluative Sciences; 2006. Available: www.ices.on.ca/ /media/ Files/Atlases-Reports/2006/CIHI-DAD-a-validation-study/Full\%20report. ashx (accessed 2015 July 15).

30. Data quality documentation for external users: national ambulatory care reporting system: 2010-2011. Ottawa: Canadian Institute for Health Information; 2011. Available: https://www.cihi.ca/en/nacrs_exec_summ_2010_ 2011_en.pdf (accessed 2015 June 15).

Affiliations: Toronto Rehabilitation Institute (Stock, Cowie, Chan, Colantonio, Wodchis, Alter, Cullen), University Health Network; Rehabilitation Sciences Institute (Stock, Chan, Colantonio), University of Toronto; Institute of Health Policy, Management and Evaluation (Colantonio, Wodchis, Alter), University of Toronto; Institute for Clinical Evaluative Sciences (Wodchis, Alter); Westpark Healthcare Centre (Cullen), Toronto, Ont.
Contributors: Nora Cullen, Angela Colantonio, Vincy Chan and David Stock conceived the study and contributed to all aspects of the study design. David Stock accessed the data, was chiefly responsible for selecting the analytical methodology and conducted all statistical analyses. David Stock and Cassie Cowie drafted the majority of the manuscript. Vincy Chan, Nora Cullen, Angela Colantonio, Walter Wodchis and David Alter contributed to data interpretation and revising the manuscript critically for important intellectual content. All of the authors approved the final version to be published and agreed to act as guarantors of the work.

Funding: This project was funded by the Physicians' Services Incorporated Foundation.

Acknowledgements: This study was supported through provision of data by the Institute for Clinical Evaluative Sciences (ICES) and Cancer Care Ontario (CCO) and through funding support to the ICES from the Ontario Institute for Cancer Research (OICR). The opinions, results and conclusions reported in this paper are those of the authors. No endorsement by the ICES, CCO or OICR is intended or should be inferred. Parts of this material are based on data and information compiled and provided by the Canadian Institute for Health Information (CIHI). However, the analyses, conclusions, opinions and statements expressed herein are those of the authors and not necessarily those of the CIHI. Finally, support was provided through a Canadian Institutes of Health Research Research Chair in Gender, Work and Health (CGW-126580), held by Angela Colantonio.

ICES disclaimer: This study was supported by the Institute for Clinical Evaluative Sciences (ICES), which is funded by an annual grant from the Ontario Ministry of Health and Long-Term Care (MOHLTC). The opinions, results and conclusions reported in this article are those of the authors and are independent from the funding sources. No endorsement by the ICES or the Ontario MOHLTC is intended or should be inferred.

Supplemental information: For reviewer comments and the original submission of this manuscript, please see www.cmajopen.ca/content/4/4/ E689/suppl/DC1 